\title{
Spatio-Temporal Perturbation of the Dynamics of the Ferroin Catalyzed Belousov-Zhabotinsky Reaction in a Batch Reactor Caused by Sodium Dodecyl Sulfate Micelles
}

\author{
Federico Rossi, Renato Lombardo, Luciana Sciascia, Carmelo Sbriziolo, and \\ Maria Liria Turco Liveri* \\ Dipartimento di Chimica Fisica “F. Accascina”, Università degli Studi di Palermo, Viale delle Scienze, Parco \\ d'Orleans II, Pad. 17, 90128 Palermo, Italy
}

Received: January 9, 2008; Revised Manuscript Received: March 18, 2008

\begin{abstract}
The effects of the anionic surfactant sodium dodecyl sulfate (SDS) on the spatio-temporal and temporal dynamics of the ferroin-catalyzed Belousov-Zhabotinsky (BZ) reaction have been studied over a wide surfactant concentration range. For the first time, investigations were performed also for unstirred systems. The presence of SDS in the reaction mixture influences the oscillatory parameters to an extent that significantly depends on the surfactant concentration. The trend of the wave speed $v$ upon the increasing amount of SDS was found to have a maximum at $[\mathrm{SDS}]=0.075 \mathrm{~mol} \mathrm{dm}^{-3}\left(v=0.071 \mathrm{~mm} \mathrm{~s}^{-1}\right)$, after which the speed decreased to $0.043 \mathrm{~mm} \mathrm{~s}^{-1}$ at [SDS] $=0.5 \mathrm{~mol} \mathrm{dm}^{-3}$, which is below the value found in the absence of the surfactant $\left(v=0.055 \mathrm{~mm} \mathrm{~s}^{-1}\right)$. The response of the oscillatory BZ system to the addition of SDS has been ascribed to two different causes: (a) the peculiar capability of the organized surfactant assemblies to affect the reactivity by selectively sequestering some key reacting species and (b) the modifications induced by SDS on the physical properties of the medium. These hypotheses have been corroborated by performing spectrophotometric investigations on the stirred BZ system. Complementary viscosity measurements gave useful hints for the clarification of the surfactant role.
\end{abstract}

\section{Introduction}

The Belousov-Zhabotinsky (BZ) reaction is the most famous and thoroughly studied chemical oscillator. It represents the catalytic oxidation of an organic substrate with active methylenic hydrogens, generally malonic acid $\left(\mathrm{CH}_{2}(\mathrm{COOH})_{2}, \mathrm{MA}\right)$, by bromate ions in a strongly acidic aqueous solution. ${ }^{1,2}$ The general stoichiometry has the form:

$$
2 \mathrm{BrO}_{3}^{-}+3 \mathrm{MA}+2 \mathrm{H}^{+} \stackrel{\text { catalyst }}{\longrightarrow} 2 \mathrm{BrMA}+4 \mathrm{H}_{2} \mathrm{O}+3 \mathrm{CO}_{2}
$$

where BrMA is bromomalonic acid $\left(\mathrm{BrCH}(\mathrm{COOH})_{2}\right)$.

The most used catalysts are metal redox couples such as $\mathrm{Ce}(\mathrm{IV}) / \mathrm{Ce}(\mathrm{III})$ or ferriin/ferroin $\left(\mathrm{Fe}(\right.$ phen $) 3^{3+} / \mathrm{Fe}($ phen $) 3^{2+}$ ). Complexes that show markedly different color in different oxidation states, like ferroin, are often used to visualize patterns and structures generated by the BZ reaction when coupled with transport phenomena. ${ }^{3}$ The BZ reaction mechanism is very complex, and the latest proposed full models for the cerium catalyzed reaction involves more than 80 elemental steps. ${ }^{4,5}$ In the Appendix section, we show a simplified model used for ferroin catalyzed BZ systems; we employed this model to perform the simulations reported in the discussion section.

Thanks to the wide variety of nontrivial behaviors manifested (multistability, oscillations, spatio-temporal chaos, chemical waves, etc.), the $\mathrm{BZ}$ reaction has become one of the most used model for studying theoretically and experimentally far from equilibrium systems and dissipative structures. ${ }^{6,7}$

* Corresponding Author: E-mail: tliveri@unipa.it. Fax: +39 091590015 Tel: +390916459849 .
The combination of a chemical oscillator with peculiar reaction environments is a subject extensively studied during the past years. In particular, examples about BZ reaction include gels, ${ }^{8}$ synthetic membranes, ${ }^{9}$ ion-exchange resins, ${ }^{10}$ micelles, ${ }^{11,12}$ polymers, ${ }^{13,14}$ water in oil reverse microemulsions, ${ }^{15,16}$ and lipid bilayers. ${ }^{17,18}$ Among the above-mentioned modifying reaction media, surfactant forming micelles revealed to be very intriguing and promising. In fact, as it is well-known, one of the most important properties of micellar solutions is their ability to selectively interact with the species present in the medium depending on their chemical proprieties such has charge, hydrophobicity, etc. The selective ability has been attributed to their solubilization sites, namely, the hydrophilic shell, the palisade layer, and the hydrophobic core. In this way, the nature of the solubilized species dictate the locus of solubilization and, thus, very hydrophilic species stay in the hydrophilic shell, amphiphilic molecules stay preferentially with the polar portion in contact with the micellar surface, and the hydrophobic portion is directed toward the core while the hydrophobic one is much more localized in the core. ${ }^{19}$

The anionic surfactant sodium dodecyl sulfate (SDS) consists of a sulfate polar head and a twelve carbon atoms in the hydrophobic tail. The choice of SDS has been mainly dictated by three of its characteristics: $:^{12}$ (a) the widespread use in many fields of science, (b) the chemical inertia toward the BZ reactants, and (c) the capability to change aggregation form only as a function of its concentration.

Small quantities of SDS (concentrations $<10^{-4} \mathrm{~mol} \mathrm{dm}^{-3}$ ) are often employed in pattern formation experiments to prevent large bubble formation and to facilitate the reproducibility of experiments. Moreover, due to its surface activity properties, SDS has often been used to favor the spreading of BZ mixtures 
over glass Petri dishes in order to create thin solution layers (almost two-dimensional). ${ }^{20-22}$

Systematic studies ${ }^{11-14}$ dealing with the effect of organized systems have been recently undertaken in our group to both elucidate the reaction mechanism and to observe the appearance, if any, of new nonlinear phenomena. In particular, the presence of SDS, both below and above critical micelles concentration ( $\mathrm{cmc}$, the concentration at which micelles are formed), influences the temporal dynamics of closed stirred BZ systems. The segregation properties of the micellar aggregates were supposed to be responsible for the effects induced on the overall kinetics of cerium, ${ }^{12}$ ruthenium, ${ }^{23}$ and ferroin ${ }^{24}$ catalyzed $\mathrm{BZ}$ reactions. In the Ce-catalyzed systems it has also been found that the BZ reaction responds in a nonlinear way to the addition of the SDS depending on the shape of the micelles, i.e. spherical or ellipsoidal. Moreover, since the SDS concentration influences in different manner the partition of some key chemical species, this reflects into different effects on the length of the preoscillatory oxidation stage (induction period).

The intriguing observed response gave us the motivation to extend the investigation for the unstirred BZ system in the presence of SDS. Thus, we have undertaken the present work, where the effects of SDS aggregates at high surfactant concentrations $\left(>10^{-2} \mathrm{~mol} \mathrm{dm}^{-3}\right)$ on the behavior of a ferroin catalyzed BZ system have been studied. It has been found that the speed of chemical waves $(v)$ is largely influenced by the presence of SDS, in particular $v$ increases up to a maximum of $0.071 \mathrm{~mm}$ $\mathrm{s}^{-1}$ for [SDS] $=0.075 \mathrm{~mol} \mathrm{dm}^{-3}$ after which it drops down to $0.043 \mathrm{~mm} \mathrm{~s}^{-1}$ for $[\mathrm{SDS}]=0.5 \mathrm{~mol} \mathrm{dm}^{-3}$, the latter being well below the value found in the absence of surfactant, which under our conditions is $0.055 \mathrm{~mm} \mathrm{~s}^{-1}$. The trend of $v$ has been explained in terms of both the segregation ability of the micelles and the viscosity of the medium. The system has been characterized by using complementary techniques and investigated from the physical and chemical point of view. The experimental results have been corroborated by performing numerical simulations.

The findings of this work are in line with previous studies on BZ/SDS systems and bring new insights in understanding the behavior of the $\mathrm{BZ}$ reaction in the presence of aggregated systems.

\section{Experimental Methods}

Chemicals. Malonic acid, sodium bromate, sulfuric acid, and ferroin $\left(\mathrm{Fe}(o \text {-phen })_{3} \mathrm{SO}_{4}\right)$ were commercial grade reactants (Fluka) and used without further purification. Sodium dodecyl sulfate (SDS) was Fluka puriss (assay $299 \%$ ) or Fluka BioChemika (assay $>99 \%$ ). The former was recrystallized at least three times by using ethanol, and the latter was used as received. However, in both cases, the purity was checked by tensiometric measurements, and the plot of surface tension as a function of surfactant concentration did not show any minimum in the cmc region. This result allows us to rule out the presence of impurities. Moreover, the $\mathrm{cmc}$ value was in good agreement with that reported in the literature. ${ }^{25}$ No significant differences were found for the effects induced by the two batches of surfactant on the BZ reaction dynamics.

Surface tension measurements were determined both in the absence and in the presence of $\mathrm{BZ}$ reactants at the concentrations used for experiments and given below in the text. Measurements were carried out by means of a KSV-Sigma 70 automatic tensiometer by using the Whilelmy plate method. The critical micelle concentration of SDS in aqueous solutions was estimated as the intersection point of the two linear plots, above and below

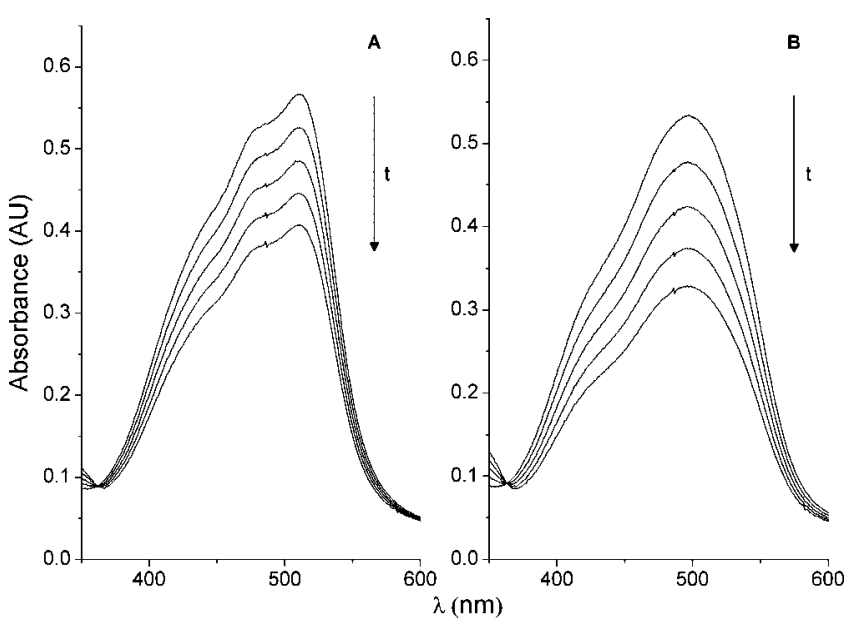

Figure 1. Spectra of ferroin in the range $350 \mathrm{~nm}<\lambda<600 \mathrm{~nm}$ for solutions in the absence (A) and in the presence (B) of micelles at [SDS] $=0.25 \mathrm{~mol} \mathrm{dm}^{-3}$. BZ reactants were present in the following concentrations for both solutions: $[\mathrm{MA}]=0.20 \mathrm{~mol} \mathrm{dm}^{-3},\left[\mathrm{H}_{2} \mathrm{SO}_{4}\right]=$ $0.07 \mathrm{~mol} \mathrm{dm}^{-3}$, [ferroin] $=3 \times 10^{-3} \mathrm{~mol} \mathrm{dm}{ }^{-3} \cdot T=24.0^{\circ} \mathrm{C}$. Arrows show time direction, and the interval between each spectra was $900 \mathrm{~s}$, both in $\mathrm{A}$ and $\mathrm{B}$.

the cmc, of the surface tension versus log of surfactant concentration. The $\mathrm{cmc}$ values under the experimental conditions used in the present work were about $2 \times 10^{-3} \mathrm{~mol} \mathrm{dm}^{-3}$. The lower value with respect to that in water is in line with the effect caused by the presence of electrolytes.

Experiments on Waves Speed. In order to have a pure reaction-diffusion system, experiments on wave propagation were performed sandwiching samples between two borosilicate optical windows (diameter $=49 \mathrm{~mm}$ ) separated by a $100 \mu \mathrm{m}$ Teflon gasket (inner diameter $=25 \mathrm{~mm}$ ). Every sample was prepared by diluting the proper amount of stock solutions in order to obtain the desired SDS concentration (all of them well above the $\mathrm{cmc}$ ) and the following initial reactant concentrations: $\left[\mathrm{BrO}_{3}{ }^{-}\right]=0.15 \mathrm{~mol} \mathrm{dm}^{-3},\left[\mathrm{H}_{2} \mathrm{SO}_{4}\right]=0.10 \mathrm{~mol} \mathrm{dm}^{-3},[\mathrm{MA}]$ $=0.20 \mathrm{~mol} \mathrm{dm}^{-3}$, [ferroin] $=3.0 \times 10^{-3} \mathrm{~mol} \mathrm{dm}^{-3}$. Waves and patterns evolution was followed by using an IEEE-1394 PixeLINK PL-A774 CCD camera equipped with a $10 \times$ close focus zoom lens and connected with a PC for data acquisition and elaboration. A narrow bandpass interference filter $(\lambda=510$ $\mathrm{nm}$ ) was used to enhance contrast between blue (ferriin, oxidized catalyst) and red substrate (ferroin, reduced catalyst). Image sequences of every experiment were taken by using a sampling time of $1 \mathrm{~s}$ for a total time of about $10 \mathrm{~min}$. The disturbance due to the bubbles resulting from $\mathrm{CO}_{2}$ production did not allow a longer recording time. The surfactant concentration was varied in the range $0.01 \leq[\mathrm{SDS}] \leq 0.50 \mathrm{~mol} \mathrm{dm}{ }^{-3}$. This concentration range was dictated by two main reasons. First, under the experimental conditions used, a red precipitate formed at [SDS] $<0.01 \mathrm{~mol} \mathrm{dm}^{-3}$. Such precipitate was formed also in the presence of SDS and ferroin without the remaining component of the BZ system. It is reasonable to suppose that the precipitation is due to the formation of an adduct between the positively charged ferroin and the negatively charged SDS head groups. The precipitate could be easily dissolved by increasing the surfactant concentration. Second, higher surfactant concentrations led to very viscous solutions which could not be easily handled. All experiments were performed at room temperature $\left(\sim 24{ }^{\circ} \mathrm{C}\right)$.

Spectrophotometric Runs. Experiments on the dynamics of $\mathrm{BZ}$ reaction, both in the absence and in the presence of SDS, were performed following the variation of ferriin concentration 
a)

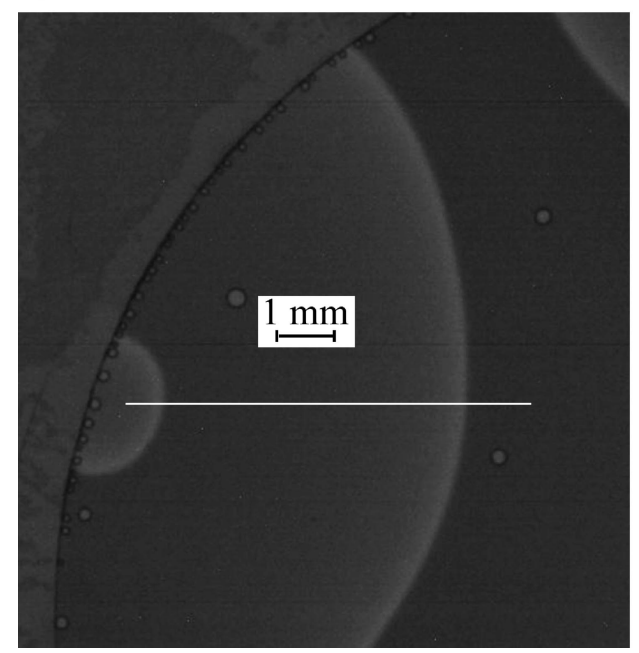

b)

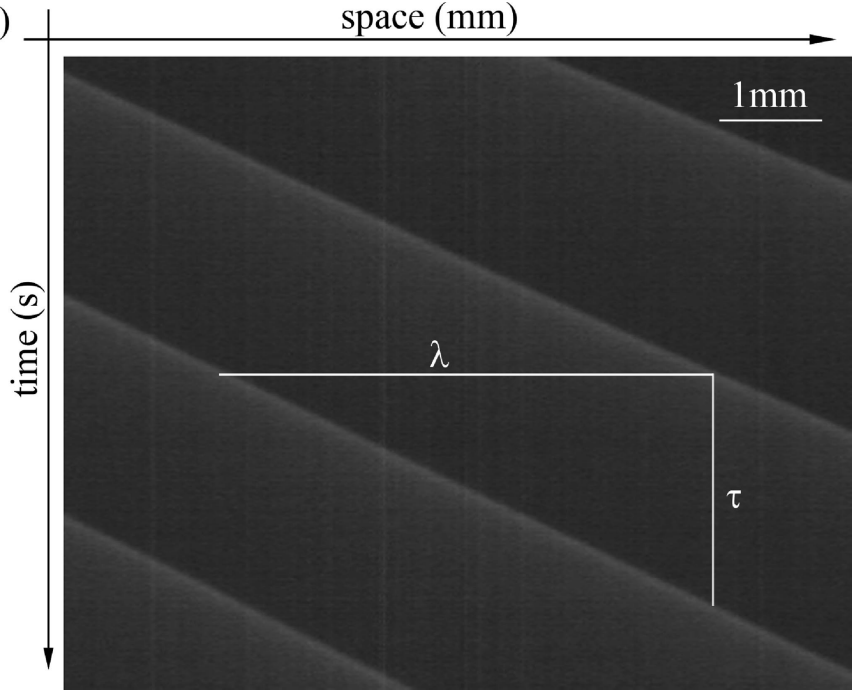

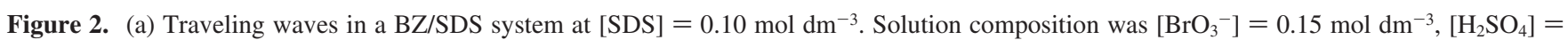
$0.10 \mathrm{~mol} \mathrm{dm}^{-3},[\mathrm{MA}]=0.20 \mathrm{~mol} \mathrm{dm}{ }^{-3}$, [ferroin] $=3.0 \times 10^{-3} \mathrm{~mol} \mathrm{dm}^{-3} . T \sim 24{ }^{\circ} \mathrm{C}$. The horizontal white bar shows the portion of reactor used to build the space-time plot reported in (b). The calculated slope of the diagonal lines reported in (b) represents the speed $v$ of the waves. $\lambda$ and $\tau$ are the wavelength and the period, respectively.

at a wavelength of $630 \mathrm{~nm}$ with a thermostatted PC-controlled spectrophotometer (Beckman DU-640) equipped with a magnetic stirring apparatus. The reactor was a quartz UV grade cuvette $(1 \times 1 \times 5 \mathrm{~cm})$ having a path length of $1 \mathrm{~cm}$. Temperature was $24.0^{\circ} \mathrm{C}$ for all experiments. Samples were prepared directly in the cuvette by mixing under vigorous stirring all reactants except ferroin with SDS stock solution in desired proportions. Finally, oscillations were started by adding ferroin in the cuvette sealed with a Teflon plug. The stirring with a reduced rate was continued during the entire course of the experiments. The solutions volume was kept at $3 \mathrm{~mL}$ for all experiments.

Concentrations of reactants used in the experiments on wave propagation led to a large production of $\mathrm{CO}_{2}$ bubbles that caused serious problems in the spectrophotometric data acquisition. Therefore, different initial concentration values, with respect to those applied for the waves experiments, have been used for the spectrophotometric runs: $\left[\mathrm{BrO}_{3}^{-}\right]=0.1 \mathrm{~mol} \mathrm{dm}^{-3},\left[\mathrm{H}_{2} \mathrm{SO}_{4}\right]$ $=0.07 \mathrm{~mol} \mathrm{dm}^{-3},[\mathrm{MA}]=0.2 \mathrm{~mol} \mathrm{dm}^{-3},[$ ferroin $]=3 \times 10^{-3}$ mol dm ${ }^{-3}$. In particular, reducing the concentrations of $\mathrm{H}_{2} \mathrm{SO}_{4}$ and $\mathrm{NaBrO}_{3}$ resulted in a "slower" version of the $\mathrm{BZ}$ reaction and consequently in an acceptable production of $\mathrm{CO}_{2}$. Nevertheless, analogous trends of the effects induced upon addiction of SDS have been observed in both cases.

Ferriin Decomposition. It is known that ferroin and ferriin decompose in the presence of strong acid: ${ }^{3,26,27}$

$$
\mathrm{Fe}(\text { phen })_{3}{ }^{n+}+3 \mathrm{H}^{+} \stackrel{k_{\mathrm{d}}}{\longrightarrow} \mathrm{Fe}^{n+}+3(\text { phen }) \mathrm{H}^{+} n=2,3
$$

Reaction 1.2 changes the global dynamics (and consequently the oscillation frequency) of the ferroin-catalyzed BZ system, ${ }^{27}$ but it reaches an appreciable rate when initial concentrations of reactants are very high and concentration of ferroin is low. ${ }^{26,28}$ Nevertheless, to verify the influence of SDS micelles on this process, experiments on ferroin decomposition were conducted spectrophotometrically. Figure 1 shows the behavior of the ferroin absorbance along a wavelength scan $(350 \mathrm{~nm}<\lambda<$ $600 \mathrm{~nm}$ ), both in the absence (A) and in the presence (B) of the surfactant. Experimental conditions were the same of those used for spectrophotometric runs described above; however, $\mathrm{BrO}_{3}{ }^{-}$ was not present.

From Figure 1 it is clear that SDS influences to some extent the decomposition process (1.2). The differences in the absorbance and in the peak shape are likely due to a strong partition of ferroin into the aggregates and to a different molar extinction coefficient caused by a different chemical surrounding. Nevertheless, the wavelength at which ferroin has an absorption maximum resulted unchanged. We also calculated the first order rate constants relative to system in Figure $1 \mathrm{~A}([\mathrm{SDS}]=0 \mathrm{~mol}$ $\left.\mathrm{dm}^{-3}\right)$ and Figure 1B $\left([\mathrm{SDS}]=0.25 \mathrm{~mol} \mathrm{dm}^{-3}\right)$, which were found to be $k_{\mathrm{d}}=1.45 \times 10^{-4} \mathrm{~s}^{-1}$ and $k_{\mathrm{d}}{ }^{\prime}=1.77 \times 10^{-4} \mathrm{~s}^{-1}$, respectively. Our experimental conditions allow us to neglect the small differences found between the constants. This is reasonable, because on the temporal scale of the observation, the BZ evolution process (1.2) is far from being complete.

Viscosity Measurements. The relative viscosities $\left(\eta_{\mathrm{r}}\right)$ of surfactant aqueous solutions were determined in the presence of BZ components, except ferroin, with the same concentrations used for the experiments on wave propagation.

The relative viscosity of the aqueous surfactant solution was determined by measuring the flow time in an Ostwald viscometer and applying the well know relationship $\eta_{r}=\eta / \eta_{0}=(t)$ $\left.t_{0}\right)\left(\rho / \rho_{0}\right)$, where $t$ and $\rho$ are the flow time and density, respectively, of the sample in the presence of SDS and $t_{0}$ and $\rho_{0}$ are those of the BZ mixture used for waves experiments (without ferroin).

The densities of the solvent and aqueous surfactant solutions were measured at $25.000 \pm 0.001{ }^{\circ} \mathrm{C}$ using a vibrating tube flow densimeter (model 03D, Sodev Inc.) sensitive to $3 \mathrm{ppm}$. The temperature was maintained constant within $0.001{ }^{\circ} \mathrm{C}$ using a closed loop temperature controller (model CT-L, Sodev Inc.). The calibration of the densimeter was made using a procedure reported in the literature. ${ }^{29}$

Data Analysis. Space-time (ST) plots were built by cutting thin slices (1 pixel) from the same region of every frame of the recorded sequences and pasting them sequentially together in a new image. Every pixel on time axis represents the image capture sampling time ( $1 \mathrm{~s})$, and space axis represents the actual space spanned by the waves. Waves speed $(v)$ was calculated from the slope of diagonal lines in ST plots. A typical 


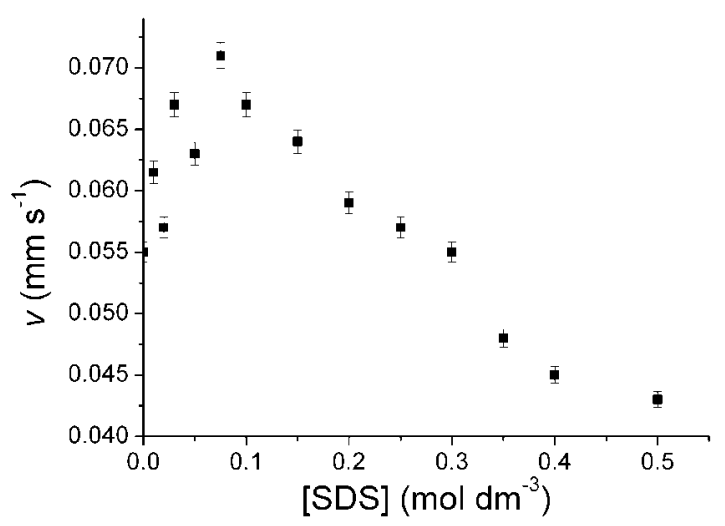

Figure 3. Wave speed $(v)$ as a function of surfactant concentration for the BZ/SDS system. Solution composition was $\left[\mathrm{BrO}_{3}{ }^{-}\right]=0.15 \mathrm{~mol}$ $\mathrm{dm}^{-3},\left[\mathrm{H}_{2} \mathrm{SO}_{4}\right]=0.10 \mathrm{~mol} \mathrm{dm}^{-3},[\mathrm{MA}]=0.20 \mathrm{~mol} \mathrm{dm}^{-3}$, [ferroin] $=$ $3.0 \times 10^{-3} \mathrm{~mol} \mathrm{dm}^{-3} . T \sim 24{ }^{\circ} \mathrm{C}$.
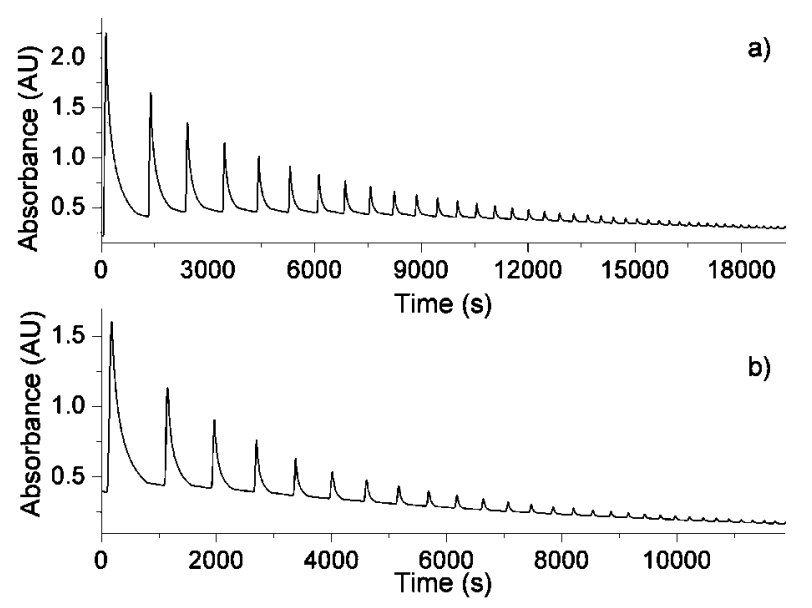

Figure 4. Time series recordings at $\lambda=630 \mathrm{~nm}$ for BZ/SDS systems (a) in the absence of surfactant and (b) in the presence of [SDS] $=0.5$ $\mathrm{mol} \mathrm{dm}{ }^{-3} \cdot\left[\mathrm{BrO}_{3}^{-}\right]=0.1 \mathrm{~mol} \mathrm{dm}^{-3},\left[\mathrm{H}_{2} \mathrm{SO}_{4}\right]=0.07 \mathrm{~mol} \mathrm{dm}^{-3}$, [MA] $=0.2 \mathrm{~mol} \mathrm{dm}^{-3}$, [ferroin] $=3 \times 10^{-3} \mathrm{~mol} \mathrm{dm}^{-3} \cdot T=24.0{ }^{\circ} \mathrm{C}$.

experiment and its relative ST plot are shown in panels a and b of Figure 2, respectively.

BZ-ferroin systems do not show any induction period before the onset of oscillations, ${ }^{3}$ therefore the main indicator about the overall dynamics of the reaction is the oscillation frequency $v$ or its reciprocal value $\tau$. In the present work, $\tau$ values have been evaluated as the temporal difference between successive peaks from the time series recorded spectrophotometrically. In particular, we refer to $\tau_{\mathrm{m}}$ which represents the mean period of the first hour of oscillations (in our systems it roughly corresponds to $4-5$ oscillations).

\section{Results and Discussion}

Waves speed $(v)$ has been measured first in the absence of surfactant and, then, over a wide SDS concentration range. Under the experimental conditions above specified, the wave speed in the absence of SDS was found to be $0.055 \mathrm{~mm} \mathrm{~s}^{-1}$ while values of $v$ are strongly influenced by the presence of SDS. In particular, Figure 3 shows the value of $v$ as a function of [SDS]. Perusal of this figure permits to identify two distinct regions of behavior:

(1) in the surfactant concentration range $0.01 \mathrm{~mol} \mathrm{dm}^{-3} \leq$ [SDS] $\leq 0.075 \mathrm{~mol} \mathrm{dm}^{-3}, v$ increased with the surfactant concentration reaching a maximum of $0.071 \mathrm{~mm} \mathrm{~s}^{-1}$ for [SDS] $=0.075 \mathrm{~mol} \mathrm{dm}^{-3}$, and (2) in the surfactant concentration range

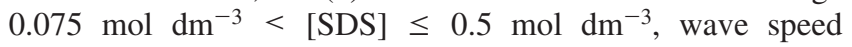

decreased down to $v=0.043 \mathrm{~mm} \mathrm{~s}^{-1}$ for [SDS] $=0.2 \mathrm{~mol}$ $\mathrm{dm}^{-3}$, that is below the value in the absence of SDS.

The trend reported in Figure 3 can be rationalized remembering that the speed of a wavefront in reactions where autocatalysis is coupled with diffusion ${ }^{30}$ is

$$
v \propto \sqrt{k D}
$$

where $D$ is the diffusion coefficient of the autocatalytic species and $k$ is the kinetic constant of the rate determinant step of the autocatalytic process. For BZ reaction, in particular, Field and Noyes $^{31}$ determined that $v$ depends on the concentrations of $\mathrm{BrO}_{3}{ }^{-}$and $\mathrm{H}_{2} \mathrm{SO}_{4}$ in addition to $k$ and $D$ :

$$
v=2\left(k_{a} D_{a}\right)^{1 / 2}\left(\left[\mathrm{H}^{+}\right]\left[\mathrm{BrO}_{3}^{-}\right]\right)^{1 / 2}
$$

where $D_{\mathrm{a}}$ is the diffusion coefficient of $\mathrm{HBrO}_{2}$ (the autocatalytic species) and $k_{\mathrm{a}}$ is the kinetic constant of the global autocatalytic process

$$
\begin{aligned}
3 \mathrm{H}^{+}+\mathrm{BrO}_{3}^{-}+2 \mathrm{Fe}(\text { phen })_{3}{ }^{2+}+ & \mathrm{HBrO}_{2} \rightarrow 2 \mathrm{HBrO}_{2}+ \\
& 2 \mathrm{Fe}(\text { phen })_{3}{ }^{3+}+\mathrm{H}_{2} \mathrm{O}
\end{aligned}
$$

Reaction 1.5 was derived from the reaction scheme of the BZ subsystem ferroin/bromate. ${ }^{28,31}$

At a fixed composition of the reaction mixture, as in our case, the speed of the fronts is determined by two concurrent factors, namely, kinetic parameters and the properties of the medium. In this perspective, the effect of the presence of SDS is not a trivial issue as it could act in different ways. In particular, the trend showed in Figure 3 seems to suggest two opposite effects depending on the surfactant concentration.

In order to separately investigate the kinetics effects, ignoring the mass transport phenomena, the BZ system has been also studied in a stirred batch reactor.

Figure 4 shows typical plots of ferriin absorbance as a function of time for a stirred $\mathrm{BZ}$ reaction in the absence (Figure $4 a$ ) and in the presence (Figure 4b) of SDS. A comparison of the two plots reveals that the presence of the anionic surfactant has a considerable effect also on the stirred system. In particular, the presence of micellized surfactant leads to a markedly shorter oscillation period $\tau$, a smaller amplitude of the oscillations, and a sensibly shorter duration of oscillating regime. As it is shown in Figure 5, the oscillation period depends on the surfactant concentration; $\tau$ drops down from about $1200 \mathrm{~s}$ in the absence of SDS to about $900 \mathrm{~s}$ for a system with [SDS] $=0.5 \mathrm{~mol} \mathrm{dm}^{-3}$. Analogous effect was previously observed for lower ranges of [SDS]. ${ }^{24}$

In this way, we may reasonably assume that the presence of SDS micelles may exert a strong influence on the kinetics of the reaction. In fact, micelles selectively interact with the chemical species present in the system. The nature and extent of the interaction depend on the chemical nature (charge and hydrophilic/hydrophobic properties) of both the SDS aggregates and the species present in solution. ${ }^{12,19}$

These findings unambiguously indicate that the addition of surfactant to the BZ mixture causes an increase of the global reaction kinetics. In particular, the absorbance and the total number of oscillation cycles, i.e. the duration of the reaction, can be ascribed to bromate depletion in the system, which in the case of the presence of surfactant aggregates appears to be faster.

Such enhancement effect can be understood in the framework of the pseudophases model.$^{32}$ In fact, in our case, the positively charged species are partitioned between the aqueous and the micellar pseudophases (the interactions of ferroin with SDS are 


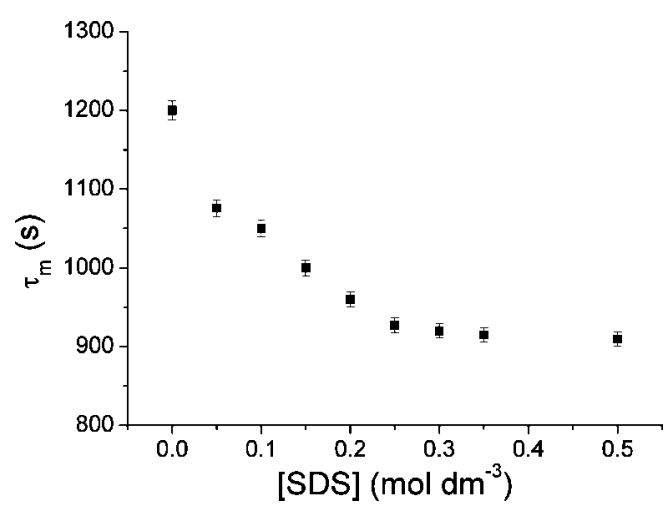

Figure 5. Mean oscillation period $\left(\tau_{\mathrm{m}}\right)$ as a function of surfactant concentration for the BZ/SDS system. Experimental conditions are the same as those reported in Figure 4.

also strongly confirmed by the precipitate formation at low SDS concentrations). This will result in an increased local concentration in the micellar pseudophase that enhances the production of bromous acid, which in turn leads to an increase of the waves speed and to a shortening of the oscillation period.

As for the oscillation period, it must be considered that any oscillation cycle is composed by a part in which ferriin concentration increases and by a second one in which ferriin is consumed. This latter part being longer than the first one under our experimental conditions, other interactions had to be taken into account in order to explain the large effect on the oscillation period. One of the processes responsible for the ferriin consumption is its reaction with the bromomalonic acid formed during the reaction ${ }^{26,33-35}$ (process R9 in the reaction scheme reported in the Appendix):

$$
\begin{aligned}
\mathrm{Fe}(\text { phen })_{3}{ }^{3+}+\mathrm{CHBr}(\mathrm{COOH})_{2} \rightleftarrows & \mathrm{Fe}(\text { phen })_{3}{ }^{2+}+ \\
& \mathrm{H}^{+}+{ }^{\bullet} \mathrm{CBr}(\mathrm{COOH})_{2}
\end{aligned}
$$

It is reasonable to think that this process can be greatly influenced by the presence of aggregates. In fact, evidence of organophilic nature of bromomalonic acid has been recently provided, ${ }^{36}$ and as previously stated, positively charged species have a great affinity with an anionic surfactant like SDS.

Process 1.6 is part of the bromide ion regeneration process (process $\mathrm{C}$ ) in the $\mathrm{FKN}$ mechanism, ${ }^{37}$ and it was studied in detail. ${ }^{27,33,35}$ Process $\mathrm{C}$ was found to be the most important step in determining the oscillation period of the $\mathrm{BZ}$ reaction, ${ }^{38}$ and thus to corroborate our hypothesis, we simulated oscillations varying the constant of the reduction step (1.6), $k_{\mathrm{r}}$. A complete model for ferroin-catalyzed BZ reaction is not still available; nevertheless, some variants of the FKN mechanism well reproduce the global oscillating behavior in a qualitative way. ${ }^{33,39}$ We performed simulations by using the model and the values of the constant reported by Benini et al. ${ }^{39}$ (also showed in the Appendix) omitting reactions involving oxygen, which, in our experimental conditions for spectrophotometric runs, are negligible. Using COPASI package, ${ }^{40}$ we increased the value of $k_{\mathrm{r}}$ starting from the value reported in literature for the reduction of ferriin in aqueous solutions without surfactant (11.7 $\left.\mathrm{mol}^{-1} \mathrm{dm}^{3} \mathrm{~s}^{-1}\right)$ until oscillations in the model resulted completely damped $\left(30.0 \mathrm{~mol}^{-1} \mathrm{dm}^{3} \mathrm{~s}^{-1}\right)$. Figure 5 shows the trend of $\tau_{\mathrm{m}}$ upon increasing $k_{\mathrm{r}}$ (both quantities along the $X$ and $Y$ axes are normalized with respect to the values for aqueous systems). The trend reported clearly indicates that a higher value of $k_{\mathrm{r}}$, as we expect from the presence of SDS micelles, results in an increased oscillation frequency. Moreover, other features

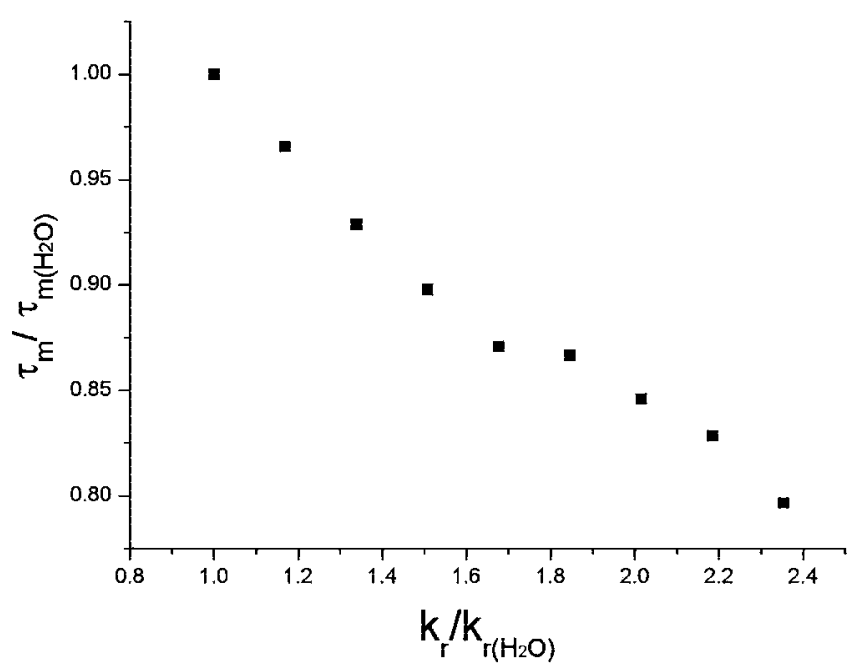

Figure 6. Simulated mean oscillation period $\left(\tau_{\mathrm{m}}\right)$ as a function of the straightforward constant $k_{\mathrm{r}}$ of the reduction process of ferriin by malonic acid. Quantities along axis are normalized with respect to the values in aqueous systems.

TABLE 1: Values of Rate Constants for Reactions (R1-R14)

\begin{tabular}{lll}
\hline reaction & \multicolumn{1}{c}{$k_{\text {forward }}$} & \multicolumn{1}{c}{$k_{\text {inverse }}$} \\
\hline R1 & $8 \times 10^{9} \mathrm{~mol}^{-2} \mathrm{dm}^{6} \mathrm{~s}^{-1}$ & $80 \mathrm{~s}^{-1}$ \\
R2 & $2.5 \times 10^{6} \mathrm{~mol}^{-2} \mathrm{dm}^{6} \mathrm{~s}^{-1}$ & \\
R3 & $3 \times 10^{3} \mathrm{~mol}^{-1} \mathrm{dm}^{3} \mathrm{~s}^{-1}$ & \\
R4 & $1.2 \mathrm{~mol}^{-3} \mathrm{dm}^{9} \mathrm{~s}^{-1}$ & $3.2 \mathrm{~mol}^{-1} \mathrm{dm}^{3} \mathrm{~s}^{-1}$ \\
R5 & $48 \mathrm{~mol}^{-2} \mathrm{dm}^{6} \mathrm{~s}^{-1}$ & $3.2 \times 10^{3} \mathrm{~s}^{-1}$ \\
R6 & $7.5-10^{4} \mathrm{~s}^{-1}$ & $1.4 \times 10^{9} \mathrm{~mol}^{-1} \mathrm{dm}^{3} \mathrm{~s}^{-1}$ \\
R7 & $0.38 \mathrm{~mol}^{-3} \mathrm{dm}^{9} \mathrm{~s}^{-1}$ & \\
R8 & $1 \times 10^{9} \mathrm{~mol}^{-2} \mathrm{dm}^{6} \mathrm{~s}^{-1}$ & \\
R9 & $11.7 \mathrm{~mol}^{-1} \mathrm{dm}^{3} \mathrm{~s}^{-1}$ & $2.2 \times 10^{8} \mathrm{M}^{-2} \mathrm{~s}^{-1}$ \\
R10 & $0.012 \mathrm{~s}^{-1}$ & $800 \mathrm{~s}^{-1}$ \\
R11 & $3.5 \times 10^{6} \mathrm{~mol}^{-1} \mathrm{dm}^{3} \mathrm{~s}^{-1}$ & \\
R12 & $6.6 \times 10^{4} \mathrm{~mol}^{-1} \mathrm{dm}^{3} \mathrm{~s}^{-1}$ & \\
R13 & $1 \times 10^{8} \mathrm{~mol}^{-1} \mathrm{dm}^{3} \mathrm{~s}^{-1}$ & \\
R14 & $1.5 \mathrm{~s}^{-1}$
\end{tabular}

like the total "lifespan" of oscillatory regime and the amplitude of single oscillations show a behavior qualitatively in accordance to that observed upon the addition of surfactant; both decreased at higher values of $k_{\mathrm{r}}$.

The proposed explanation can thus account for the catalytic effect on the kinetics of the BZ reaction, and this fact explains the increment of $v$ upon addiction of surfactant to the BZ mixture. Nevertheless, it does not explain the decrease of $v$ to values below those obtained in aqueous solution. Thus, to understand the trend observed for the wave speed at higher SDS concentrations (Figure 3), the effect of the SDS micelles on the medium properties has to play a relevant role. Most likely these effects must be ascribed to variations of the medium viscosity due to the formation of aggregated systems. To corroborate our hypothesis, we measured the viscosities of the BZ/SDS solutions with increasing SDS content. Figure 6 shows the trend of relative viscosity $\left(\eta_{\mathrm{r}}\right)$ as a function of surfactant concentration. A linear region between $0.01 \mathrm{~mol} \mathrm{dm}^{-3}<$ [SDS] $<0.3 \mathrm{~mol} \mathrm{dm}^{-3}$ followed by a significant increase of $\eta_{\mathrm{r}}$ can be detected. The discontinuity point at $[\mathrm{SDS}] \approx 0.3 \mathrm{~mol} \mathrm{dm}^{-3}$ is most likely due to a transition between two micelles forms, namely, from an elongated shape to an entangled one. Analogous trends which support our present hypothesis, have been previously $^{12}$ obtained for the BZ/SDS systems under different experimental conditions. The observed changes in the medium viscosity will lead to lower diffusivities of the species in 


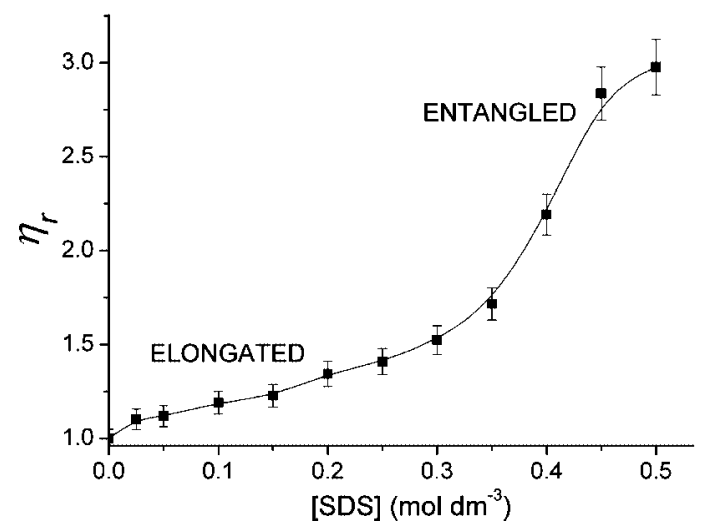

Figure 7. Relative viscosity $\left(\eta_{\mathrm{r}}\right)$ as a function of surfactant concentration of aqueous SDS solutions in the presence of $\left[\mathrm{BrO}_{3}{ }^{-}\right]=0.15 \mathrm{~mol}$ $\mathrm{dm}^{-3},\left[\mathrm{H}_{2} \mathrm{SO}_{4}\right]=0.10 \mathrm{~mol} \mathrm{dm}^{-3},[\mathrm{MA}]=0.20 \mathrm{~mol} \mathrm{dm}^{-3} . T=24.0$ ${ }^{\circ} \mathrm{C}$. The solid line is merely used as guidance for the readers.

solution. Such an effect is predominant at higher SDS concentrations resulting in a decrease of wave speed.

\section{Concluding Remarks}

The ferroin catalyzed Belousov-Zhabotinsy (BZ) oscillating system responds in a peculiar way to the addition of increasing amount of the anionic surfactant sodium dodecyl sulfate (SDS) in unstirred closed reactors. The values of some parameters, i.e., wave speed and oscillation period, depend on the surfactant concentration used, which dictates the shape of the aggregated systems. The observed effects have been ascribed to the peculiar ability of the aggregated systems to selectively sequester some key reacting species. Proof has been provided by studying the BZ system perturbed by the SDS under stirred batch conditions. In addition, explanation for the behavior of wave speed in unstirred systems has been given on the basis of the effects of two types of micelles on the physical properties of the medium. The proposed existence of two kind of aggregated systems was supported by performing viscosity measurements on the aqueous SDS solutions.

\section{Appendix}

In this section the full scheme of the ferroin catalyzed model taken from Benini et al. ${ }^{39}$ is reported. Values for the forward and reverse rate constants are reported in Table 1.

$$
\begin{gathered}
\mathrm{HOBr}+\mathrm{Br}^{-}+\mathrm{H}^{+} \rightleftarrows \mathrm{Br}_{2}+\mathrm{H}_{2} \mathrm{O} \\
\mathrm{Br}^{-}+\mathrm{HBrO}_{2}+\mathrm{H}^{+} \rightarrow 2 \mathrm{HOBr} \\
2 \mathrm{HBrO}_{2} \rightarrow \mathrm{BrO}_{3}^{-}+\mathrm{HOBr}+\mathrm{H}^{+} \\
\mathrm{Br}^{-}+\mathrm{BrO}_{3}^{-}+2 \mathrm{H}^{+} \rightleftarrows \mathrm{HOBr}+\mathrm{HBrO}_{2} \\
\mathrm{BrO}_{3}^{-}+\mathrm{HBrO}_{2}+\mathrm{H}^{+} \rightleftarrows \mathrm{Br}_{2} \mathrm{O}_{4}+\mathrm{H}_{2} \mathrm{O} \\
\mathrm{Br}_{2} \mathrm{O}_{4} \rightleftarrows 2 \mathrm{BrO}^{-}
\end{gathered}
$$

$\mathrm{Fe}(\text { phen })_{3}{ }^{2+}+\mathrm{BrO}_{3}^{-}+2 \mathrm{H}^{+} \rightarrow$

$$
\mathrm{Fe}(\text { phen })_{3}^{3+}+\mathrm{BrO}_{2}^{\cdot}+\mathrm{H}_{2} \mathrm{O}(\mathrm{R} 7)
$$

$$
\mathrm{Fe}(\text { phen })_{3}{ }^{2+}+\mathrm{BrO}_{2}^{\bullet}+\mathrm{H}^{+} \rightarrow \mathrm{Fe}(\text { phen })_{3}{ }^{3+}+\mathrm{HBrO}_{2}
$$

$$
\begin{aligned}
\mathrm{Fe}(\text { phen })_{3}{ }^{3+}+\mathrm{BrCH}(\mathrm{COOH})_{2} \rightleftarrows & \mathrm{Fe}(\text { phen })_{3}{ }^{2+}+ \\
& { } \mathrm{CBr}(\mathrm{COOH})_{2}+\mathrm{H}^{+}
\end{aligned}
$$

$$
\begin{gathered}
\mathrm{BrCH}(\mathrm{COOH})_{2} \rightleftarrows(\mathrm{HOOC}) \mathrm{CBr}=\mathrm{C}(\mathrm{OH})_{2}(\mathrm{R} 10) \\
(\mathrm{HOOC}) \mathrm{CBr}=\mathrm{C}(\mathrm{OH})_{2}+\mathrm{Br}_{2} \rightarrow \mathrm{Br}_{2} \mathrm{C}(\mathrm{COOH})_{2}+ \\
\mathrm{Br}^{-}+\mathrm{H}^{+}(\mathrm{R} 11) \\
(\mathrm{HOOC}) \mathrm{CBr}=\mathrm{C}(\mathrm{OH})_{2}+\mathrm{HOBr} \rightarrow \mathrm{Br}_{2} \mathrm{C}(\mathrm{COOH})_{2}+\mathrm{H}_{2} \mathrm{O}
\end{gathered}
$$

\section{$2 \mathrm{CBr}(\mathrm{COOH})_{2}^{\bullet}+\mathrm{H}_{2} \mathrm{O} \rightarrow \mathrm{BrCOH}(\mathrm{COOH})_{2}+$}

$\mathrm{BrCH}\left(\mathrm{COOH}_{2}(\mathrm{R} 13)\right.$

$$
\mathrm{BrCOH}(\mathrm{COOH})_{2} \rightarrow \mathrm{Br}^{-}+\mathrm{CO}(\mathrm{COOH})_{2}+\mathrm{H}^{+}(\mathrm{R} 14)
$$

Acknowledgment. The authors thank the Università degli Studi di Palermo for financial support (Research Funds ex quota $60 \%$ ). Thanks are also due to C. Caruso for the experimental help.

\section{References and Notes}

(1) Belousov, B. P. In A Periodic Reaction and its mechanism; Medgiz: Moscow; 1958, pp 145-147.

(2) Zaikin, A. N.; Zhabotinsky, A. M. Nature. 1970, 225, 535-537.

(3) Taylor, A. F. Prog. React. Kinet. Mech. 2002, 27, 247-325.

(4) Gyorgyi, L.; Turanyi, T.; Field, R. J. J. Phys. Chem. 1990, 94, $7162-7170$.

(5) Hegedus, L.; Wittmann, M.; Noszticzius, Z.; Yan, S. H.; Sirimungkala, A.; Forsterling, H. D.; Field, R. J. Faraday Discuss. 2001, 120, 21-38.

(6) Epstein, I. R.; Pojman, J. A. An Introduction to Nonlinear Chemical Dynamics: Oscillations, Waves, Patterns, and Chaos; Oxford University Press: New York, 1998

(7) Biophys. Chem. 1998, 72 (1-2). Special Issue on Nonlinear Phenomena in Biochemical and Cellular Processes.

(8) Takeoka, Y.; Watanabe, M.; Yoshida, R. J. Am. Chem. Soc. 2003, $125,13320-13321$.

(9) Winston, D.; Arora, M.; Maselko, J.; Gaspar, V.; Showalter, K. Nature. 1991, 351, 132-135.

(10) Maselko, J.; Showalter, K. Nature. 1989, 339, 609-611.

(11) Rustici, M.; Lombardo, R.; Mangone, M.; Sbriziolo, C.; Zambrano, V.; Liveri, M. L. T. Faraday Discuss. 2001, 120, 39-51.

(12) Sciascia, L.; Lombardo, R.; Liveri, M. L.T. J. Phys. Chem. B 2007, $111,1354-1360$, and references therein.

(13) Lombardo, R.; Sbriziolo, C.; Liveri, M. L. T.; Pelle, K.; Wittmann, M.; Noszticzius, Z. In Nonlinear Dynamics in Polymeric Systems; Pojman J. A., Tran-Cong-Miyata, Q., Eds.; ACS: Washington, DC, 2004; Vol. 869, pp 292-308.

(14) Sciascia, L.; Lombardo, R.; Liveri, M. L. T. Chem. Phys. Lett. 2006, 430, 67-70.

(15) Vanag, V.; Epstein, I. Phys. Rev. Lett. 2001, 87, 228301.

(16) Vanag, V. K. Phys. Usp. 2004, 47, 923-941.

(17) Magnani, A.; Marchettini, N.; Ristori, S.; Rossi, C.; Rossi, F.; Rustici, M.; Spalla, O.; Tiezzi, E. J. Am. Chem. Soc. 2004, 126, 1140611407.

(18) Ristori, S.; Rossi, F.; Biosa, G.; Marchettini, N.; Rustici, M.; Tiezzi, E. Chem. Phys. Lett. 2007, 436, 175-178.

(19) Fendler, J. Membrane Mimetic Chemistry; John Wiley \& Sons Inc: New York, 1983.

(20) Luengviriya, C.; Storb, U.; Hauser, M. J. B.; Muller, S. C. Phys. Chem. Chem. Phys. 2006, 8, 1425-1429.

(21) Lazar, A.; Noszticzius, Z.; Forsterling, H.; Nagy-Ungvárai, Z. Physica D. 1995, 84, 112-119.

(22) Belmonte, A.; Flesselles, J. M.; Ouyang, Q. Europhys. Lett. 1996, $35,665-670$.

(23) Maritato, M.; Nikles, J.; Romsted, L. S.; Tramontin, M. J. Phys. Chem. 1985, 89, 1341-1344.

(24) Paul, A. J. Phys. Chem. B. 2005, 109, 9639-9644.

(25) Quina, F. H.; Nassar, P. M.; Bonilha, J. B. S.; Bales, B. L. J. Phys. Chem. 1995, 99, 17028-17031.

(26) Chou, Y. C.; Lin, H. P.; Sun, S. S.; Jwo, J. J. J. Phys. Chem. 1993, 97, 8450-8457.

(27) Yoshikawa, K. Bull. Chem. Soc. Jpn. 1982, 55, 2042-2045.

(28) Keki, S.; Magyar, I.; Beck, M. T.; Gaspar, V. J. Phys. Chem. 1992, 96, 1725-1729.

(29) De Lisi, R.; Lazzara, G.; Milioto, S.; Muratore, N. J. Phys. Chem. B. 2003, 107, 13150-13157.

(30) Luther, R.; Arnold, R.; Showalter, K.; Tyson, J. J. Chem. Educ. 1987, 64, 740-742. 
(31) Field, R. J.; Noyes, R. M. J. Am. Chem. Soc. 1974, 96, 20012006.

(32) Dwars, T.; Paetzold, E.; Oehme, G. Angew. Chem., Int. Ed. 2005, 44, 7174-7199.

(33) Rovinsky, A.; Zhabotinsky, A. J. Phys. Chem. 1984, 88, 60816084.

(34) Hegedus, L.; Forsterling, H.; Onel, L.; Wittmann, M.; Noszticzius, Z. J. Phys. Chem. A. 2006, 110, 12839-12844.

(35) Mrakavova, M.; Melichercik, M.; Olexova, A.; Treindl, L. Collect. Czech. Chem. Commun. 2003, 68, 23-34.
(36) Inomoto, O.; Abe, K.; Amemiya, T.; Yamaguchi, T.; Kai, S. Phys. Rev. E. 2000, 61, 5326-5329.

(37) Field, R. J.; Koros, E.; Noyes, R. M. J. Am. Chem. Soc. 1972, 94 , $8649-8664$.

(38) Edelson, D.; Thomas, V. M. J. Phys. Chem. 1981, 85, 1555-1558.

(39) Benini, O.; Cervellati, R.; Fetto, P. Int. J. Chem. Kinet. 1998, 30, 291-300.

(40) http://www.copasi.org/tiki-index.php?page=homepage.

JP8003739 